\title{
Push-out bond strength of fiber posts to root dentin using glass ionomer and resin modified glass ionomer cements
}

Jefferson Ricardo PEREIRA ${ }^{1}$, Ricardo Abreu da ROSA², Marcus Vinícius Reis SÓ ${ }^{2}$, Daniele AFONSO ${ }^{1}$, Milton Carlos $\mathrm{KUGA}^{3}$, Heitor Marques HONÓRIO ${ }^{4}$, Accácio Lins do VALLE ${ }^{5}$, Hugo Alberto VIDOTTI ${ }^{5}$

\footnotetext{
1- Department of Prosthodontics, Dental School, University of Southern Santa Catarina, Tubarão, SC, Brazil.

2- Department of Conservative Dentistry, Federal University of Rio Grande do Sul, Porto Alegre, RS, Brazil.

3- Department of Endodontics, School of Dentistry, Univ. Estadual Paulista (UNESP), Araraquara, SP, Brazil.

4- Department of Pediatric Dentistry, Orthodontics and Community Health, Bauru School of Dentistry, University of São Paulo, Bauru, SP, Brazil.

5- Department of Prosthodontics, Bauru School of Dentistry, University of São Paulo, Bauru, SP, Brazil.
}

Corresponding address: Jefferson Ricardo Pereira - Rua Recife, n. 200 - Ap 201 - Tubarão - SC - Brazil - 88701-420 - Phone/Fax: +55 48 9988 4271 e-mail: jeffripe@rocketmail.com

Submitted: September 11, 2013 - Modification: February 26, 2014 - Accepted: March 31, 2014

\section{ABSTRACT}

\begin{abstract}
O bjective: The purpose of this study was to assess the push-out bond strength of glass fiber posts to root dentin after cementation with glass ionomer (GICs) and resinmodified glass ionomer cements (RMGICs). Material and Methods: Fifty human maxillary canines were transversally sectioned at $15 \mathrm{~mm}$ from the apex. Canals were prepared with a step back technique until the application of a \#55 K-file and filled. Post spaces were prepared and specimens were divided into five groups according to the cement used for post cementation: Luting \& Lining Cement; Fuji II LC Improved; RelyX Luting; Ketac Cem; and Ionoseal. After cementation of the glass fiber posts, all roots were stored at $100 \%$ humidity until testing. For push-out test, 1-mm thick slices were produced. The push-out test was performed in a universal testing machine at a crosshead speed of $0.5 \mathrm{~mm} / \mathrm{min}$ and the values (MPa) were analyzed by Kolmogorov-Smirnov and Levene's tests and by two-way ANOVA and Tukey's post hoc test at a significance level of 5\%. Results: Fiber posts cemented using Luting \& Lining Cement, Fuji II LC Improved, and Ketac Cem presented the highest bond strength to root dentin, followed by RelyX Luting. Ionoseal presented the lowest bond strength values $(P>0.05)$. The post level did not influence the bond strength of fiber posts to root dentin $(P=0.148)$. The major cause of failure was cohesive at the cement for all GICs and RMGICs. Conclusions: Except for Ionoseal, all cements provided satisfactory bond strength values.
\end{abstract}

Keywords: Endodontics. Post and core technique. Dental cements. Glass ionomer cements. Shear strength.

\section{INTRODUCTION}

Extensively damaged teeth have been maintained in function through the association between endodontic and prosthetic treatments. The loss of coronal tooth structure results in using the root canal to retain the direct or indirect restoration. Fiber posts are an alternative to traditional cast post and cores and ceramic posts because they present elastic modulus similar to that of root dentin. Thus, the risk of root fractures decreases ${ }^{25}$. In addition, fiber posts minimize dentin removal, preserving root structure and strength, and due to their translucency better aesthetic properties are observed ${ }^{1}$. Prefabricated fiber posts simplify the restorative procedures because all steps are performed by the dentist in a single visit.

The dislodgement of the fiber posts is reported as the main cause of failure and must be related to damages on the cement layer caused by functional loads ${ }^{6,28}$. Bond strength of fiber posts to root dentin is further challenged by the limited capacity to dissipate polymerization shrinkage stresses of resin cements since root canal geometric 
features are highly unfavorable ${ }^{4}$. The high C-factor is responsible for disrupting the cement/dentin interface, creating gaps and impairing the bond sealing of resin cements ${ }^{23,26}$. The dislocation resistance of adhesive-bonded fiber posts is largely derived from sliding friction instead of true adhesion to root dentin ${ }^{23}$. Normally, cement-dentin interface is more susceptible to adhesive failures in comparison with cement-post interface, especially due to reactivation of the fiber post surface via chemomechanical pretreatments ${ }^{12}$.

In this context, glass ionomer (GICs) and resinmodified glass ionomer cements (RMGICs), initially used for cementation of metallic cast post and cores or metaloceramic and metal free crowns, have been used as alternative to resin cements for fiber post cementation $^{5,18-22}$. GICs release fluoride, although the ability of this leached fluoride to provide longterm protection against dental caries in dentin has never been proven ${ }^{27}$. When GIC cements are used, the elimination of smear layer interferences allows intimate contact of the GICs and RMGICs with the dentin surface 21,22 . RMGICs are stronger than conventional glass ionomer cements ${ }^{16}$ and also release fluoride. The main drawback of GICs is their setting reaction, since they do not reach their maximal strength for many days ${ }^{10}$. Therefore, any core preparation using handpiece on the same post cementation visit may weaken the immature cement layer ${ }^{17}$.

GICs and RMGICs interact chemically with tooth structure, based on ionic binding of the multiple carboxylic groups of polyalkenoic acid with calcium abundantly available in hard tooth tissue ${ }^{14}$. They present more favorable viscoelastic properties to the preservation of bond integrity than the stiffer resin-based cements during the polymerization shrinkage?. Moreover, GICs and RMGICs present postmaturation hygroscopic expansion which offsets their initial setting shrinkage and the interface dentin/cement remains more steady ${ }^{29}$. Thus, the residual water source within the dentinal tubules may be advantageously utilized to achieve postmaturation hygroscopic expansion of GICs and RMGICs that are employed for cementation of fiber posts ${ }^{6}$.

Many techniques and luting materials have been tested to cement fiber posts to root dentin, but the effect on push-out bond strength of different GICs remain in doubt. Therefore, the aim of this study is to compare the bond strength of glass fiber posts to root dentin after cementation with GICs and RMGICs. The null hypothesis is that there are no differences on bond strength values among the tested cements and among the post levels for each cement.

\section{MATERIAL AND METHODS}

Fifty maxillary canine human teeth with similar dimensions were transversally sectioned to standardize the root length at $15 \mathrm{~mm}$. Proximal radiographs were performed to confirm the presence of only one root canal. All the roots were observed at $8 \mathrm{x}$ magnification with a stereomicroscope (Zeiss Stemi SV6; Carl Zeiss, Jena, Germany) to exclude

\begin{tabular}{|c|c|c|}
\hline Cements & Manufacturer & Composition \\
\hline $\begin{array}{l}\text { Luting \& Lining Cement } \\
\qquad \begin{array}{l}\text { (Glass ionomer } \\
\text { cement) }\end{array}\end{array}$ & GC Corp., Tokyo, Japan & $\begin{array}{l}\text { Powder: Fluoro Alumino-silicate glass (amorphous). } \\
\text { Liquid: Distilled water, Polyacrylic acid, } \\
\text { 2-Hydroxyethylmethacrylate (HEMA), Urethanedimethacrylate } \\
\text { (UDMA). Conditioner: Citric Acid, Distilled water, Iron (III) } \\
\text { chloride (Ferric chloride), Food additive Blue No. } 1 .\end{array}$ \\
\hline $\begin{array}{l}\text { Fuji II LC Improved } \\
\text { (Resin-modified glass } \\
\text { ionomer cement) }\end{array}$ & GC Corp., Tokyo, Japan & $\begin{array}{l}\text { Powder: Alumino-silicate glass. } \\
\text { Liquid: HEMA, Polyacrylic acid, UDMA, Proprietary ingredient, } \\
2,2,4 \text {,trimethyl hexa methylene dicarbonate. }\end{array}$ \\
\hline $\begin{array}{l}\text { RelyX Luting Plus } \\
\text { (Resin-modified glass } \\
\text { ionomer cement) }\end{array}$ & 3M ESPE, St. Paul, USA & $\begin{array}{l}\text { Paste A: Fluoroaluminosilicate (FAS) glass, Proprietary } \\
\text { reducing agent, HEMA, Water, Opacifying agent. } \\
\text { Paste B: Methacrylated Polycarboxylic acid, BisGMA, HEMA, } \\
\text { Water, Potassium persulfate, Zirconia silica filler. }\end{array}$ \\
\hline $\begin{array}{l}\text { Ketac Cem } \\
\text { (Glass ionomer } \\
\text { cement) }\end{array}$ & 3M ESPE, St. Paul, USA & $\begin{array}{l}\text { Powder: Glass powder, pigments, Polycarboxylic acid. } \\
\text { Liquid: Tartaric acid, water, conservation agents. }\end{array}$ \\
\hline $\begin{array}{l}\text { lonoseal } \\
\text { (Glass ionomer } \\
\text { cement) }\end{array}$ & $\begin{array}{l}\text { VOCO America Inc., Riarcliff } \\
\text { Manor, USA }\end{array}$ & BIS-GMA BIS-DMA, Urethanedimethacrylatye, HEDMA. \\
\hline
\end{tabular}

Figure 1- Description of the cements and their chemical composition 
those with external cracks.

Size 15 K-files (Dentsply Maillefer, Ballaigues, Switzerland) were inserted into the root canal until their tips became visible outside of the apical foramen. Then, the working lengths were established by subtracting $1 \mathrm{~mm}$ of these measures. Canals were prepared with a step back technique until the application of a \#55 K-file. Roots were flushed with $1 \mathrm{~mL}$ of $1 \%$ sodium hypochlorite $(\mathrm{NaOCl})$ and $1 \mathrm{~mL}$ of $17 \%$ ethylenediaminetetraacetic acid (EDTA) alternately after each file change. Final flush was performed with $2 \mathrm{~mL}$ of saline and then dried with paper points (Tanari, Tamariman Industrial LTDA, Macaçaruru, AM, Brazil). Thereafter, the roots were filled with endodontic sealer (Sealer 26; Dentsply Maillefer) and gutta-percha FM cones (Tanari, Tamariman Industrial LTDA) by cold lateral compaction and stored at $37^{\circ} \mathrm{C}$ and $100 \%$ humidity for one week to permit the sealers to set.

The partial filling removal was initially performed with a heated instrument, and next the post space was prepared using a Largo drill \#4 (Dentsply Maillefer) at a depth of $10 \mathrm{~mm}$. After partial filling removal, the canals were flushed with $2 \mathrm{~mL}$ of $1 \%$ sodium hypochlorite and $2 \mathrm{~mL}$ of saline.

Previously to the post cementation, the glass fiber posts (Reforpost; Angelus, Londrina, PR, Brazil) were sectioned using diamond burs \#3230 (KG Sorensen, Cotia, SP, Brazil) under water cooling to standardize the post length in $14 \mathrm{~mm}$. Thereafter, the fiber posts were cleaned with $95 \%$ ethyl alcohol and dried with air spray.

The specimens were randomly divided into five groups $(n=10)$ according to the cement used for post cementation as follow: Ionoseal (VOCO America Inc., Riarcliff Manor, USA); Luting \& Lining Cement (GC Corporation, Tokyo, Japan); Fuji II LC Improved (GC Corporation); Rely X Luting 2 (3M ESPE, St. Paul, USA) and Ketac Cem (3M ESPE) (Figure 1).

All cements were manipulated according to the manufacturer's instructions and placed into the root canal with a Lentulo spiral, the fiber post was positioned, and the excess of cement was removed using a microbrush. All specimens were stored in wet environment (100\% humidity) until testing.
All the roots were transversally sectioned in a sectioning machine (Isomeet 1000, Buehler, Lake Bluff, USA). Three 1-mm-thick slices were obtained per root at $1 \mathrm{~mm}, 5 \mathrm{~mm}$, and $9 \mathrm{~mm}$ from their cervical portion. Thus, each slice represents different post level in the same root (cervical, medium, and apical).

For push-out testing, each slice was positioned on a metallic device with a central opening $(\varnothing=2$ $\mathrm{mm}$ ) larger than the canal diameter. The push-out test was performed in a universal testing machine (Emic DL - 1000, São José dos Pinhais, PR, Brazil) at a crosshead speed of $0.5 \mathrm{~mm} /$ minute. A metallic cylinder (Øextremity $=1 \mathrm{~mm}$ ) induced a load in an apical to coronal direction on the post without applying any pressure to the cement and/or dentin. The maximum value for post dislodgement (in Newtons) and the thickness of the canal diameter were measured with a digital caliper (Digimess, São Paulo, SP, Brazil) and recorded.

The bond strength $(\sigma)$ in MPa was obtained with the formula $\sigma=F / A$, where $F=l o a d$ for specimen rupture $(N)$ and $A=$ bonded area $\left(\mathrm{mm}^{2}\right)$. To determine the bonded interfacial area, the formula to calculate the lateral area of a circular straight cone with parallel bases was used. The formula is defined as: $A=n g(R 1+R 2)$, where $n=3.14, g=$ slant height, $\mathrm{R} 1=$ apical radius, $\mathrm{R} 2=$ coronal radius. To determine the slant height, the following calculation was used: $g^{2}=\left(h^{2}+[R 2-R 1]^{2}\right)$, where $h=$ section height.

Representative specimens from the five groups were selected for scanning electron microscopy (SEM) analysis. The selected specimens were mounted on a metallic stub, sputter coated with gold (Denton Vacuum, Moorestown, USA) and observed under a scanning electron microscope (JEOL, Tokyo, Japan) at different magnifications (50x, 75x, 100x, 350x, 500x, 1,000x).

Kolmogorov-Smirnov and Levene's tests were used to evaluate the distribution and homogeneity of the data, respectively. Next, the data were analyzed by two-way ANOVA and Tukey's post hoc test (the variables of the study were cement in five levels and post level in three levels). The significance level was set to $5 \%$.

Table 1- Mean and standard deviation (MPa) of push-out bond strength values according to the tested cements and the root canal sections

\begin{tabular}{cccccc}
\hline Groups & Lining Cement & $\begin{array}{c}\text { Lining Cement } \\
\text { LC Improved }\end{array}$ & RelyX Luting & Ketac Cem & lonoseal \\
\hline Cervical & $17.9(7.6)^{\mathrm{a}}$ & $19.4(3.4)^{\mathrm{a}}$ & $8.2(5.8)^{\mathrm{b}}$ & $12.0(5.3)^{\mathrm{a}}$ & $3.7(2.5)^{\mathrm{b}}$ \\
Intermediate & $16.9(5.6)^{\mathrm{a}}$ & $15.5(7.4)^{\mathrm{a}}$ & $10.3(7.5)^{\mathrm{b}}$ & $18.6(5.5)^{\mathrm{a}}$ & $2.2(2.1)^{\mathrm{b}}$ \\
Apical & $19.5(4.8)^{\mathrm{a}}$ & $17.5(7.4)^{\mathrm{a}}$ & $12.8(4.8)^{\mathrm{b}}$ & $16.9(6.1)^{\mathrm{a}}$ & $0.5(0.5)^{\mathrm{b}}$ \\
Average & $18.1(6.0)^{\mathrm{a}}$ & $19.6(13.4)^{\mathrm{a}}$ & $10.6(6.4)^{\mathrm{b}}$ & $16.1(6.2)^{\mathrm{a}}$ & $2.1(2.2)^{\mathrm{b}}$ \\
\hline
\end{tabular}

Same lowercase letters (rows) indicate absence of difference by two-way ANOVA test $(\alpha=0.05)$ 


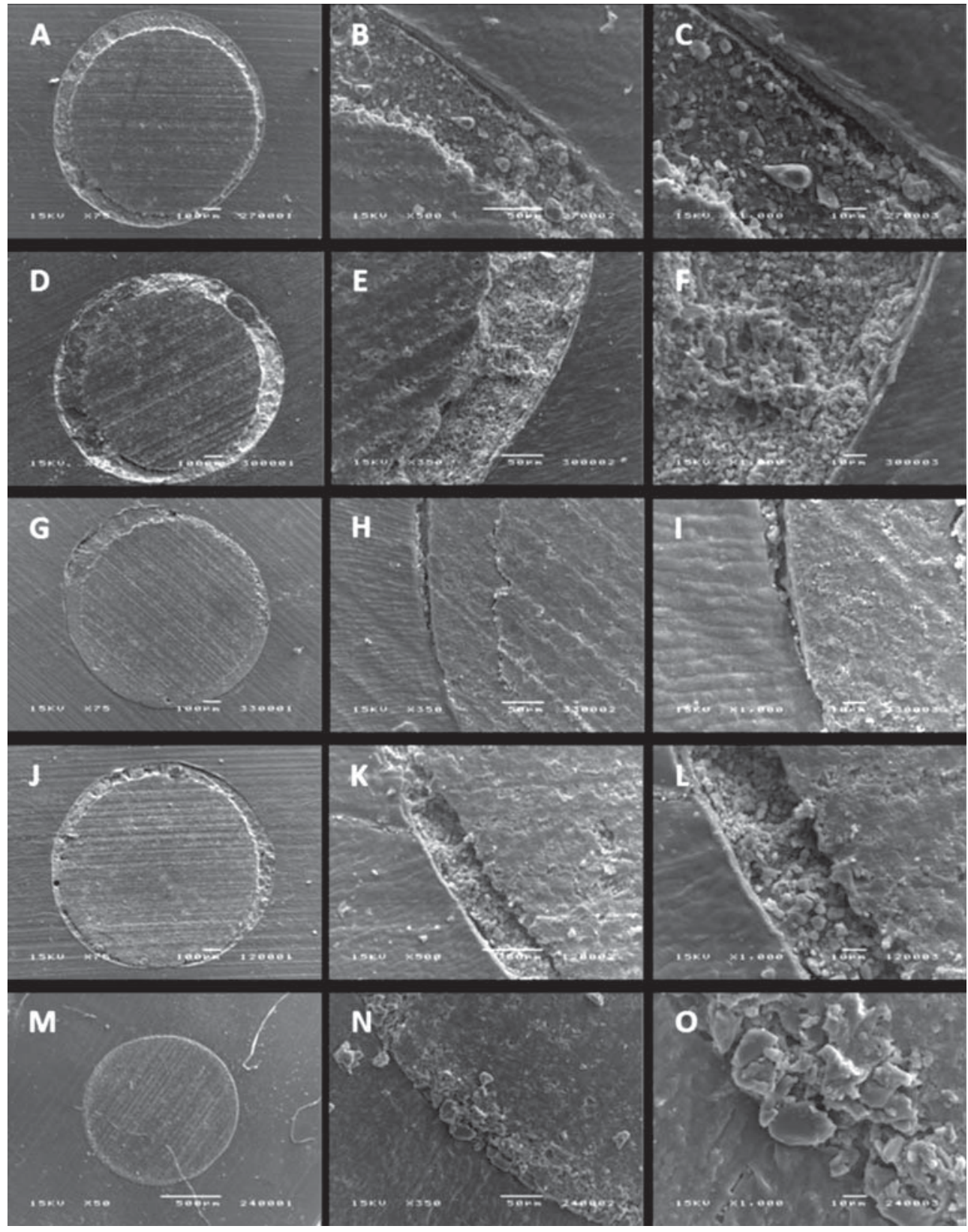

Figure 2 - Scanning electron microscopy photomicrographs of fiber post/cement and cement/dentin interfaces. (A, B, C) Luting \& Lining Cement; (D, E, F) Fuji II Cement LC Improved; (G, H, I) RelyX Luting; (J, K, L) Ketac Cem; and (M, N, O) lonoseal

\section{RESULTS}

The two-way ANOVA revealed that only the cement variable affected the push-out bond strength values $(P=0.0001)$. The post level, in turn, did not influence the bond strength of fiber posts to root dentin $(P=0.148)$. The interaction between groups is shown in Table 1 . The Tukey's post hoc test demonstrated that fiber posts cemented using Luting \& Lining Cement, Fuji II Cement LC Improved, and Ketac Cem presented the highest bond strength to root dentin, followed by RelyX Luting. Ionoseal presented the lowest bond strength values $(P>0.05)$. Moreover, the major cause of failure was cohesive at the cement for all GICs and RMGICs.

\section{DISCUSSION}

The results of this study rejected the null hypothesis that there would not be differences of bond strength values among the cements; however, the null hypothesis that there would not be differences among the posts' levels was accepted.

Nowadays, the restoration of endodontically treated teeth is based on materials that have an elastic modulus similar to that of dentin, that are capable of creating homogeneous stress 
distribution, and that are able to decrease the incidence of catastrophic root fractures ${ }^{1}$. In this scenario, fiber posts and resin-based cements are gradually replacing zinc phosphate and metallic cast post and cores; similarly, GICs and RMGICs have been used not only for restoration or crown cementation but also for post cementation ${ }^{20}$. The results of the current study indicate that the bond strength values ranged between 0.5 MPa and 19.6 $\mathrm{MPa}$ with significant differences according to the cement used for post cementation $(P<0.05)$, but with no influence of the post level $(P>0.05)$.

Several methods have been used for bond strength analysis, including tensile, microtensile, pull-out and push-out tests ${ }^{9}$. The push-out test was performed because it provides smaller adhesive areas, more uniform stress distribution on the adhesive interface, few lost specimens during experimentation, low standard deviation values, and ease of execution ${ }^{24}$. The literature presents a wide range of dentin slices thickness ( $4 \mathrm{~mm}$ to 1 $\mathrm{mm})^{8,13}$. However, recent studies have employed $1 \mathrm{~mm}$-thick slices for push-out testing, since they present lower friction areas and minor chances of results overestimation in comparison with thicker slices. The main limitation of this study is that the teeth were not aged. Although fatigue tests did not influence the bond strength of fiber posts to root dentin when they were cemented with resin cements $2,3,28$, the behavior of GICs and RMGICs under the same conditions remains unclear.

GICs and RMGICs present interconnected setting reactions, which are based on acid-base components. Fluoride ions and metal are released from the glass by polyacrylic acid protons. The high aqueous phase $\mathrm{pH}$ causes polysalt precipitates to form from the migrating ions, which act as crosslinks to the polyacrylic acid chains ${ }^{10}$. The setting time takes few minutes, according to the sealer composition, temperature and moisture; however, further maturation occurs over time ${ }^{10}$. On the other hand, at the resinous part of the RMGICs, the reaction develops quickly, and it depends of the monomer and its mobility and diffusion. The concentration and mobility of monomer decrease during the formation of cross-linked matrix networks. Thus, the polymer chain propagation also reduces.

The dentin pretreatment is essential for smear layer removal and hybrid layer formation, allowing the HEMA (2-hydroxyethylmethacrylate) to penetrate the exposed collagen fiber network ${ }^{5}$. Smear layer can break cohesively and fail as a result of polymerization shrinkage ${ }^{21}$. The elimination of smear layer interferences allows intimate contact of the GICs and RMGICs with the dentin surface ${ }^{5}$. Previous studies reported that cavity conditioners are effective in improving the bond strength of
GICs and RMGICs to dentin and enamel 5,21,22. Furthermore, Cardoso, et al. ${ }^{5}$ (2011) observed a decrease of $43 \%$ in bond strength of RMGICs to dentin when cavity conditioners were not used. For this purpose, polyacrylic, maleic and polycarboxylic acids have been used as conditioners ${ }^{22}$. In the current study, for groups in which root dentin was pretreated with polyalnenoic-acid (Luting \& Lining Cement and Fuji II LC Improved), bond strength was superior to that of Ionoseal and RelyX Luting $(P<0.05)$, which did not receive any pretreatment as recommended by their manufacturers. Marchan, et al. ${ }^{15}$ (2005) found inferior bond strength values for Luting \& Lining Cement in comparison with resin cement after tensile testing; however, the root dentin was not pretreated. These aspects highlight the importance of removing smear layer in order to improve the bond strength of GICs and RMGICs to root dentin.

The partial removal of smear layer promoted by conditioners may also contribute to dentin permeability increase, since the acid-base setting reaction is favored by additional source of water ${ }^{5}$. This may promote GI maturation at the interface, rendering the bond of the RMGIC to dentin more resistant to degradation over time ${ }^{16}$. The low bond strength values achieved with RelyX Luting can be attributed to its application over the smear layer. No acidic pretreatment is recommended by the manufacturers prior to cementation. The retention provided by RelyX Luting is more dependent on frictional retention than on its chemical bond to root dentin.

The post level did not influence the bond strength of fiber posts to root dentin $(P>0.05)$. Contrarily to dual-polymerized resin cements, the bond strength of GICs and RMGICs is not influenced by root level ${ }^{19}$. Resin cements need a reliable bonding interface that is difficult to obtain, especially at the apical level of the post space. The absence of hybrid layer on the adhesive interface may contribute to these differences when fiber posts are cemented with resin cements ${ }^{18}$. Finally, the difficulty of access of light to the deepest region of the root canal also explains the worse behavior of resin cements at the apical portion of the post space. Since GICs and RMGICs do not depend on hybrid layer formation or access of light, they did not present differences of bond strength among the root levels. Additionally, glass ionomer cements adhere to root dentin by chemical and micromechanical retention ${ }^{30}$.

Ketac Cem is a conventional GIC that contains no covalent cross-linking and is therefore more likely to undergo water degradation ${ }^{11}$. Conventional glass ionomers are susceptible to water dehydration and crazing during the initial setting reaction ${ }^{11}$. The resultant microcracks would act to initiate and facilitate crack propagation within the cement 
matrix during testing. Nonetheless, the bond strength values presented in Ketac Cem group were similar to Luting \& Lining Cement and Fuji II LC Improved.

Ideally, the cements for post cementation must provide bonding to fiber post and root dentin and gap-free interfaces that produces high interfacial strength $^{6}$. The adhesion within the root canal is impaired due to the high C-factor encountered in deep class I cavities, especially when resin cements are used ${ }^{4}$. In such cases, the stress is so high that the adhesive interface is compromised. Moreover, the application and handling techniques can influence the bond strength of adhesive and self-adhesive cements ${ }^{26}$. In view of that, more realistic concepts of retention have been employed to improve the retention of fiber posts. Therefore, GICs and RMGICs present a suitable property that increases the frictional resistance of fiber posts to root dentin. The postmaturation hygroscopic expansion offsets the shrinkage of GICs and RMGICs ${ }^{6}$. Fuji Plus, Fuji Cem and Ketac Cem exhibited increased retention strengths after water sorption in comparison with resin cements ${ }^{6}$. Such findings must be highlighted, since, clinically, the residual water present within the dentinal tubules cannot be completely removed, dried by paper points, leading to an inevitable and desirable hygroscopic expansion. Pereira, et al. ${ }^{18}$ (2013) found great bond strength values when fiber posts were cemented with GICs and RMGICs. Such results can be attributed to methodological features, because all roots were manipulated in a wet environment (i.e., all roots remained immersed in distilled water) during cementation, which favored the hygroscopic expansion ${ }^{18}$.

In addition, Figure 2 presents absence of gaps between post, cement and dentin in all tested cements. These findings must also be attributed to the hygroscopic expansion presented by GICs and RMGICs. Such characteristic leads to effective frictional retention between root canal walls and cement and between cement and fiber post. Since the major cause of failure was cohesive at cement, the higher bond strength values observed for Luting \& Lining Cement, Fuji II LC Improved, and Ketac Cem groups may also be related with their cohesive properties, which must be superior to Ionoseal and RelyX luting.

Limitations of this study were the fact that it was an in vitro investigation, which does not fully replicate oral conditions, and the use of a single load for testing the fracture strength of endodontically treated teeth. For more meaningful results, future studies should incorporate thermal and fatigue cycling of the specimens. Although resin cements still are the first choice for post cementation, the GICs and RMGICs seem to be an alternative material to retain glass fiber posts. Except for Ionoseal, all cements presented satisfactory bond strength values.

\section{CONCLUSIONS}

The following conclusions can be drawn: (1) the bond strength of fiber posts to root dentin varied according to the cement used for post cementation; (2) higher bond strength values were observed when fiber posts were cemented using Luting \& Lining Cement, Fuji II LC Improved, and Ketac Cem; (3) the post level did not influence the bond strength of fiber posts to root dentin; and (4) the major cause of failure was cohesive at the cement.

\section{ACKNOWLEDGEMENTS}

This study was supported, in part, by grants from PIBIC/CNPq - National Council for Scientific and Technological Development. The authors also acknowledge Angelus and 3M for donating part of the materials used in this study. The authors declare no conflict of interest.

\section{REFERENCES}

1- Bitter K, Noetzel J, Stamm O, Vaudt J, Meyer-Lueckel H, Neumann K, et al. Randomized clinical trial comparing the effects of post placement on failure rate of postendodontic restorations: preliminary results of a mean period of 32 months. J Endod. 2009;35(11):1477-82.

2- Bolhuis $P$, de Gee A, Feilzer A. Influence of fatigue loading on four post-and-core systems in maxillary premolars. Quint Int. 2004;35(8):657-67.

3- Bolhuis P, de Gee AJ, Feilzer A. The influence of fatigue loading on the quality of the cement layer and retention strength of carbon fiber post-resin composite core restorations. Oper Dent. 2005;30(2):220-7.

4- Bouillaguet S, Troesch S, Wataha JC, Krejci I, Meyer JM, Pashley $\mathrm{DH}$. Microtensile bond strength between adhesive cements and root canal dentin. Dent Mat. 2003;19(3):199-205.

5- Cardoso MV, Delmé KI, Mine A, Neves AA, Coutinho E, De Moor RJ, et al. Towards a better understanding of the adhesion mechanism of resin-modified glass-ionomers by bonding to differently prepared dentin. J Dent. 2011;38(11):921-9.

6- Cury AH, Goracci C, Lima Navarro MF, Carvalho RM, Sadek FT, Tay FR, et al. Effect of hygroscopic expansion on the push-out resistance of glass ionomer-based cements used for the luting of glass fiber posts. J Endod. 2006;32(6):537-40.

7- Dauvillier BS, Feilzer A, De Gee AJ, Davidson CL. Visco-elastic parameters of dental restorative materials during setting. J Dent Res. 2000;79(3):818-23.

8- Durão Mauricio PJ, González-López S, Aguilar-Mendoza JA, Félix S, González-Rodríguez MP. Comparison of regional bond strength in root thirds among fiber-reinforced posts luted with different cements. J Biomed Mater Res B Appl Biomater. 2007;83(2):36472.

9- Goracci C, Grandini S, Bossù M, Bertelli E, Ferrari M. Laboratory assessment of the retentive potential of adhesive posts: a review. J Dent. 2007;35(11):827-35.

10- Khoroushi M, Karvandi TM, Sadeghi R. Effect of prewarming and/or delayed light activation on resin-modified glass ionomer bond strength to tooth structures. Oper Dent. 2012;37(1):54-62. 
11- Knobloch LA, Kerby RE, Seghi R, Berlin JS. Fracture toughness of resin-based luting cements. J Prosthet Dent. 2000;83(2):204-9. 12- Kulunk S, Kulunk T, Yenisey M. Effects of different surface pre-treatments on the bond strength of adhesive resin cement to quartz fiber post. Acta Odontol Scand. 2012;70(6):547-54.

13- Le Bell AM, Tanner J, Lassila LVJ, Kangasniemi I, Vallittu PK. Bonding of composite resin luting cement to fiber reinforced composite root canal posts. J Adhes Dent. 2004;6(4):319-25.

14- Lin A, McIntyre NS, Davidson RD. Studies on the adhesion of glass-ionomer cements to dentin. J Dent Res. 1992;71(11):183641.

15- Marchan S, Coldero L, Whiting R, Barclay S. In vitro evaluation of the retention of zirconia-based ceramic posts luted with glass ionomer and resin cements. Braz Dent J. 2005;16(3):213-7.

16- Marquezan M, Fagundes TC, Toledano M, Navarro MF, Osorio R. Differential bonds degradation of two resinmodified glassionomer cements in primary and permanent teeth. J Dent. 2009;37(11):857-64.

17- Morgano SM, Brackett SE. Foundation restorations in fixed prosthodontics: current knowledge and future needs. J Prosthet Dent. 1999;82(6):643-57.

18- Pereira JR, Valle AL, Ghizoni JS, Lorenzoni FC, Ramos MB, Só MV. Push-out bond strengths of different dental cements used to cement glass fiber posts. J Prosthet Dent. 2013;110(2):134-40. 19- Pereira JR, Valle AL, Ghizoni JS, Só MV, Ramos MB, Lorenzoni FC. Evaluation of push-out bond strength of four luting agents and SEM observation of the dentine/fibreglass bond interface. Int Endod J. 2013;46(10):982-92.

20- Pereira JR, Vidotti HA, Valle AL, Pamato S, Ghizoni JS, Honório $\mathrm{HM}$, et al. SEM analysis and push-out bond strength of fiberglass posts luted with different cements of glass-ionomer in humid environment: pilot test. J Res Dent. 2013;1(1):83-90.

21- Pereira PN, Yamada T, Inokoshi S, Burrow MF, Sano H, Tagami J. Adhesion of resin-modified glass ionomer cements using resin bonding systems. J Dent. 1998;26(5-6):479-85.
22- Pereira PN, Yamada T, Tei R, Tagami J. Bond strength and interface micromorphology of an improved resin-modified glass ionomer cement. Am J Dent. 1997;10(3):128-32.

23- Reis KR, Spyrides GM, Oliveira JA, Jnoub AA, Dias KR, Bonfantes G. Effect of cement type and water storage time on the push-out bond strength of a glass fiber post. Braz Dent J. 2011;22(5):359-64.

24- Rosa RA, Bergoli CD, Kaizer OB, Valandro LF. Influence of cement thickness and mechanical cycling on the push-out bond strength between posts and root dentin. Gen Dent. 2011;59(4):e156-61.

25- Santos-Filho PCF, Verissimo C, Queiroz CL, Saltarelo RC, Soares CJ, Barretos CF. The effect of type post, crown, and ferrule presence on stress distribution of maxillary central incisors with weakened roots: finite element analysis. J Res Dent. 2013;1(2):154-64.

26- Shiratori FK, Valle AL, Pegoraro TA, Carvalho RM, Pereira JR. Influence of technique and manipulation of self-adhesive resin cements used to cement intraradicular posts. J Prosthet Dent. 2013;110(1):56-60.

27- Staninec M, Giles WS, Saiku JM, Hattori M. Caries penetration and cement thickness of three luting agents. Int J Prost. 1998;1(3):259-63.

28- Valandro LF, Baldissara P, Galhano GA, Melo RM, Mallmann A, Scotti $R$, et al. Effect of mechanical cycling on the push-out bond strength of fiber posts adhesively bonded to human root dentin. Oper Dent. 2007;32(6):579-88.

29- Yiu CK, Tay FR, King NM, Pashley DH, Carvalho RM, Carrilho MR. Interaction of resin-modified glass-ionomer cements with moist dentine. J Dent. 2004;32(7):521-30.

30- Young AM, Rafeeka SA, Howlett JA. FTIR investigation of monomer polymerisation and polyacid neutralisation kinetics and mechanisms in various aesthetic dental restorative materials. Biomaterials. 2004;25(5):823-33. 